\title{
0 pergaminho de Mefistófeles: teoria, pesquisa e desventuras medievalistas no conhecimento sociolópico
}

Leandro Duarte Rust*

\begin{abstract}
Resumo: Este artigo propõe uma análise crítica, embora breve, do "lugar social" no qual é realizada a pesquisa brasileira acerca da história medieval. Desse vasto e complexo tema destacamos uma problemática específica: a apropriação da teoria sociológica formulado por Pierre Bourdieu por parte dos medievalistas brasileiros em resposta a um importante dilema enfrentado em especial na década de 1990. O artigo encontra-se dividido fundamentalmente em três partes: a primeira consiste na apresentação desse impasse que se formou no interior do medievalismo nacional; a segunda seção estabelece uma visão geral crítica dos fundamentos da teoria sociológica de Pierre Bourdieu; por fim, segue-se, na terceira parte, a confrontação entre os postulados norteados da chamada "teoria dos campos" e sua pertinência para o estudo da civilização medieval. O cerne deste artigo consiste em propor reflexões que estimulem um debate mais acurado acerca das razões intelectuais e das relações de poder que orientam o exercício do ofício do medievalista no Brasil.
\end{abstract} Palavras-chave: História medieval. Pensamento sociológico. Historiografia. Teoria. Pierre Bourdieu.

\footnotetext{
* Professor do Programa de Pós-Graduação em História da Universidade Federal de Mato Grosso (UFMT). E-mail: leandrorust@yahoo.com.br.
} 
"Esbaforis-vos num corropio à roda da ciência, e cada qual por fim... pilha o que pilha. Saber aproveitar as circunstâncias é que cifra o saber."

Mefistófeles, Fausto.

\section{O dilema: apontamentos sobre a medievalística brasileira}

A institucionalização da pesquisa em história medieval nas universidades brasileiras é algo recente. Diferentemente do que ocorreu noutras paragens acadêmicas da América Latina,' como a Argentina, somente a partir da década de 1980 se deu a instauração de uma produção historiográfica nacional especializada em Idade Média. Certamente nosso interesse acadêmico sobre essa fatia da história ocidental é mais antigo. Ele remonta aos anos de 1940 e às teses de doutorado defendidas por Eurípides Simões de Paula - O comércio varegue e o Grão-Principado de Kiev -, Eduardo d'Oliveira França - $O$ poder real em Portugal e as origens do absolutismo - e Pedro Moacyr Campos - Alguns aspectos da Germânia antiga, através dos autores clássicos. Isso sem esquecer os debates acerca do "feudalismo brasileiro" e das raízes medievais advindas da colonização portuguesa, discussão promovida em especial por Nelson Werneck Sodré (1976) e Alberto Passos Guimarães (1963). Porém, esta mescla de trabalhos pioneiros e incursões ensaístas não configurava um território de investigações institucionalizado. Prova disso é que

até o fim da década de 90 haviam poucos doutores especializados em Idade Média atuando nas instituições de ensino superior do Brasil; eram raros os títulos sobre o medievo publicados por editoras brasileiras; não circulavam periódicos nacionais especializados exclusivamente no medievo; as bibliotecas universitárias praticamente não possuíam em seus acervos periódicos e livros sobre temáticas medievais; não existia uma associação que agregasse, em 
nível nacional, os interessados no ensino e na pesquisa da Idade Média; núcleos de medievalistas locais e/ou regionais eram praticamente inexistentes. (SILVA, 2004, p. 87).

A consolidação acadêmica da pesquisa brasileira em história medieval é um capítulo de nossa trajetória intelectual escrito nos tempos do pós-ditadura militar (FRANCO JR.; BASTOS, 20022003; RUST; BASTOS, 2008).

Os leitores familiarizados com as reviravoltas do conhecimento histórico ao longo do século XX provavelmente encontrarão nessa afirmação algo muito sugestivo. Afinal, ela situa a institucionalização de pesquisa medievalista brasileira na confluência de dois movimentos intelectuais que moldaram decisivamente a maneira como os historiadores atuais exercem seu ofício.

O primeiro deles foi o desembarque triunfal da chamada nouvelle histoire deste lado do Atlântico. Valendo-se de traduções portuguesas, obras como $A$ sociedade feudal, de Marc Bloch, ou o verdadeiro best-seller de Emmanuel Le Roy Ladurie, Montaillou, tomaram de assalto livrarias e bibliotecas universitárias do Novo Mundo. Com isso, as mesas de trabalho de nossos estudiosos foram povoadas por uma vasta bibliografia, cujos títulos anunciavam um ambicioso projeto de renovação do saber histórico. Seguir as propostas temáticas professadas por aquele que foi considerado "o mais influente grupo de historiadores do mundo atual" (HUNT, 1986 , p. 209, tradução nossa) era visto como a principal forma de inserir-se no que havia de mais inovador e engrandecedor na nova escrita anunciada para a história. E como uma prestigiosa parcela dos annalistes era de medievalistas - como Jacques Le Goff e Georges Duby -, tudo parecia indicar que o passado medieval era um dos maiores propiciadores dessa celebrada "nova história", seu catalisador e objeto de vanguarda.

Diante da opinião amplamente disseminada de que os tempos medievais compunham para nós, brasileiros, um passado "estrangeiro", "estranho", "pertencente ao outro" e - nas avaliações mais amenas - "indireto" ou "distante", nossos pesquisadores podiam agora revidar com a certeza de que a realização de suas investigações assegurava a modernização do papel do historiador 
nesta terra Brasilis, livrando-o de amarras conceituais retrógadas e despindo-o de arcaicas convenções teórico-metodológicas. ${ }^{1}$ Essa serventia institucional encontrada nas contribuições da chamada "Escola dos Annales" ajuda-nos a compreender porque as linhas de investigações e os repertórios temáticos apresentados por estes "mandarins da historiografia" (CANTOR, 1991, p. 124-160) foram recebidos em nossos programas de pós-graduação como "vetores paradigmáticos". Muito da afirmação universitária de nossos medievalistas se deve à incorporação e promoção acadêmica dessa produção bibliográfica francesa. Afinal, as obras annalistes proporcionaram-lhes seus "clássicos fundadores", a medida de suas problemáticas de estudo, os critérios de avaliação de seus projetos de pesquisa. O reverso da moeda desses ganhos institucionais foi a forma como embarcamos na chamada "história das mentalidades" (MEGILL, 2004; REIS, 2000). O Brasil foi pródigo em promover a premissa de que investigar o passado equivalia, em larga medida, a aventurar-se nos domínios dos "utensílios mentais", "inconscientes coletivos", "longas durações". O elástico conceito de mentalités foi uma matriz de contribuições importantes para o amadurecimento do medievalismo brasileiro: ela nutriu autores de contribuições substanciais para a medievalística nacional; dela foram retiradas orientações temáticas que ainda hoje exercem forte magnetismo sobre as elaborações de nossas dissertações e teses (MACEDO, 2003). Portanto, pavimentando o sinuoso caminho que conduziu à projeção da história medieval nas universidades brasileiras, as perspectivas historiográficas vinculadas à nowvelle histoire e ao estudo das mentalidades se converteram no "paradigma forte" de nosso medievalismo.

No entanto, eis que, naqueles mesmos anos da década de 1980, começamos a sentir, com maior consistência, as repercussões do segundo movimento intelectual: a propagação de um agressivo revisionismo epistemológico usualmente designado "pós-modernismo". Tendo por espinha dorsal a guinada linguístico-pragmática operada pela filosofia contemporânea já nos primeiros decênios do século XX (OLIVEIRA, 2006), esse descentrado e complexo leque de proposições intelectuais manejou grande vigor crítico contra pressupostos epistemológicos que há décadas sustentavam 
a produção do conhecimento científico. Uma intensa saraivada de questionamentos colocou na berlinda intelectual proposições epistemológicas até então tidas como basilares e, por isso, óbvias. Esse foi o caso do valor universalista conferido a entidades como a "natureza" e a "verdade", da premissa de uma acessibilidade - ou uma transposição - do empírico pelo narrativo (e vice-versa), da convicção na viabilidade de saberes da grande abrangência, notabilizados por alcances totalizadores, as chamadas "macronarrativas" (BARTHES, 1967; LYOTARD, 2006; NICHOLSON, 1990; RORTY; GHIRALDELLI JR., 2006; WHITE, 2001).

Tais indagações, fulminantes em inúmeros casos, atingiram em cheio a elaboração do saber histórico como um todo. Porém, foram particularmente graves para a nouvelle histoire. Isso porque a nova e agitada atmosfera intelectual amplificou as críticas que já despontavam a respeito dos estudos annalistes e seu apego à noção de mentalidades. Colocados em evidência como o establishment da operação historiográfica, os nouveaux foram intimamente associados ao processo de desgaste da "história total", de debilitação das formas de problematização das relações presente-passado e de aproximações pouco cautelosas entre o método historiográfico e os limites da composição narrativa. Arrastados pela torrente "pósmoderna", grandes nomes franceses da história medieval foram confrontados com o preço cobrado pelo estilhaçamento da "história em migalhas" (DOSSE, 2003). Para grande parte dos medievalistas nacionais as implicações desse declínio do prestígio annaliste eram particularmente graves. Afinal, quando Jacques Le Goff ou Georges Duby eram atingidos por críticas como "a Nouvelle Histoire veiculava um programa absurdo, uma esterilidade logo evidente, um simples episódio de um fenômeno de alcance mundial que convém reduzir às justas proporções" (FONTANA, 2004, p. 390-394), a própria cidadania institucional do medie-valismo brasileiro cambaleava. Nossos pesquisadores viram muitos de seus "clássicos" listados como exemplares do "absurdo de se aceitar uma total indigência teórica” (CARDOSO, 1988, p. 99). Com recém-implantados pulmões annalistes, nossos pesquisadores do medievo encontravam dificuldades singulares para respirar na atmosfera da "crise dos paradigmas". 
Assim, desde meados da década de 1990, esta tem sido uma característica marcante do multifacetado lugar social da pesquisa da história medieval no Brasil: o desafio de encontrar-se atado a dois vínculos conflitantes. Isto é, à manifesta dívida - e talvez mesmo dependência - em relação ao legado historiográfico annaliste, de um lado, e à necessidade de responder e adequar-se aos desafios "pós-modernos", de outro. Nossos medievalistas parecem vivenciar em termos institucionais um dilema semelhante ao que foi atribuído a Fausto. Como o célebre personagem de Goethe, eles se veem apanhados por um impasse inadiável de escolher entre caminhos que se dividem e se opõem. E como ocorreu na conhecida estória, encarando essa bifurcação, eles se dão conta de que tal escolha é, de fato, uma aposta que coloca em jogo o caráter ativo e criador de sua existência intelectual.

\section{A promessa: a "teoria dos campos"}

As reações de nossos pesquisadores diante desse impasse formam um caleidoscópio de opções intelectuais. Alguns se engajaram pela preservação do olhar annaliste. Assumiram a tarefa de dar continuidade às propostas essenciais da nouvelle histoire, buscando revitalizá-las com reformulações teóricas propiciadas por conceitos como "imaginário" ou "pensamento analógico". No extremo oposto, houve quem contestasse a necessidade de superar esse olhar. Estes, por sua vez, certificaram as obras de um Le Goff ou um Duby como imprescindíveis, mas inevitavelmente superadas: legitimavam, assim, sua inclinação para escolher os prismas oferecidos pelo "pós-modernismo teórico". Entre essas duas pontas intelectuais, se dispuseram diversas opções, como a dos que propuseram um retorno tácito a matizes historicistas, os que fortaleceram sua adesão ao materialismo histórico-dialético, os que estreitaram laços com a antropologia, os que aderiram à crítica foucaultiana, ou mesmo os muitos que praticam uma espécie de sincretismo teórico, alternando filiações intelectuais a cada novo trabalho. Porém, em nossa opinião, uma postura vem ganhando 
cada vez mais espaço na pesquisa brasileira em história medieval: a apropriação de contribuições da recente teoria sociológica. Em especial, aquela identificada com o francês Pierre Bourdieu e a "teoria dos campos".

A sociologia dos "campos sociais" confeccionada por Pierre Bourdieu tornou-se, para muitos medievalistas brasileiros, uma alternativa segura e confiável de conciliação e avanço historiográficos em meio aos tempos pós-modernos. Trilhando esse caminho sociológico, eles acreditaram ter em mãos um modo eficaz para superar as deficiências teórico-metodológicas atribuídas à nouvelle histoire; sem, todavia, causar o rompimento dos laços que os ligam ao seu "paradigma fundador". Para compreender como isso se faria possível é imprescindível manter em mente uma apreciação de conjunto, ainda que cercada de limitações, da proposta bourdieusiana de análise dos fenômenos sociais. Vamos a ela.

A abrangente abordagem sociológica de Pierre Bourdieu fundamentou-se na noção de trabalho, tomada de empréstimo do modelo paradigmático de produção-trabalho operado por Karl Marx. Tal como para o autor d'O capital, é a partir de como as coletividades conduzem as diferentes modalidades de trabalho que o investigador bourdieusiano mapeia os distintos jogos em que é realizada a ação social. Isso significa que o sociólogo francês reteve como centro gravitacional de sua teoria um dos pressupostos centrais do pensamento marxista: o trabalho como processo par excellence de objetivação da vida em sociedade (LEFEBVRE, 1966; MARX, 1983; ROSDOLSKI, 2001). Eis um bom exemplo. Marx qualificava uma ação ou atividade como trabalho na medida em que ela desempenhava o papel de uma modalidade de integração humana, implicando um fazer não mecânico, uma prática não instintiva, mas potencializadora da matéria trabalhada, um processo capaz de converter matérias em produtos socializáveis e dotados de valor (MARX, 1983). Bourdieu modelou a noção de "trabalho" nos mesmos termos epistemológicos, isto é, como um veículo de expressão e inter-relação social. Um conceito que pressupõe a sociabilidade. Haja vista, por exemplo, que, em sua perspectiva, uma prática religiosa confinada à condição de experiência meramente subjetiva - como algo incapaz de se tornar intercambiável 
entre um grupo, por menor que este fosse - não poderia ser classificada como "trabalho religioso" (BOURDIEU, 1998a, p. 27-78).

Contudo, diferentemente de Karl Marx, a noção de trabalho não tem aqui um conteúdo específico, de teor materialista. Isto é, ela não está preenchida com a centralidade dos modos de produção, das relações com a propriedade, da exploração econômica. Não está, portanto, primordialmente atada às condições materiais da existência (MARX, 1977, p. 30, 1983, p. 149-155). Em Bourdieu a noção de trabalho corresponde a um modelo relacional sem conteúdo predeterminado. À luz do pensamento formulado por esse sociólogo francês, o referido conceito não remete, a priori, a operações que envolvam a materialidade, ele não tem por pressuposto designar modos de agir intrinsecamente físicos, maquinais, empíricos. Isto é, trabalho é uma forma de interação mantida pelos homens com todos os atributos do mundo que os rodeia, sejam esses atributos materiais ou simbólicos. É uma espécie de ossatura real de inúmeros processos da vida em sociedade. Tentemos essa argumentação de outra forma. Na obra sociológica bourdieusiana o termo trabalho designa uma faceta da ontologia humana em geral, um modus operandi da organização e da inscrição de diversas ocorrências e objetos na realidade socialmente vivida, quer eles pertençam à materialidade das forças produtivas ou não (ROBBINS, 2002; VANDENBERGHE, 1999). Desse modo, a sociologia de Bourdieu dilatou o conceito marxista de trabalho. Ela o elevou à condição de um arquétipo da realidade social, de uma matriz aberta, combinatória e em constante movimento. Uma lábil gramática sócio-histórica de princípios de organização e transformação da vida humana, quer sejam eles econômicos, jurídicos, políticos, artísticos ou religiosos. O que nos permite falar em "trabalho econômico", "trabalho jurídico", "trabalho político", "trabalho artístico", "trabalho religioso" (BENOIST, 1975; DOSSE, 1994).

Para a sociologia bourdieusiana a noção de trabalho é "o" fio da meada que permite desembaraçar os novelos que envolvem a existência coletiva. Basta recordar como o próprio sociólogo definiu os domínios da vida em sociedade segundo os diferentes tipos de trabalho coletivamente efetivados. Distinguir as variadas modalidades sociais de trabalho consistia no próprio método para divisar 
os "espaços relativamente autônomos, microcosmos dotados de leis próprias" (BOURDIEU, 2004, p. 20) em que estão distribuídas as relações sociais. Logo, à tipologia de trabalhos empreendidos por uma coletividade corresponde um escalonamento dos diferentes campos que constituem uma sociedade. Se preferirmos, podemos dispor a mesma argumentação nos termos mais simples desta equação elementar: trabalho religioso $=$ campo religioso; trabalho artístico = campo artístico; trabalho político = campo político; e assim por diante.

Como é de se supor, a centralidade do conceito de trabalho é marcante no processo de análise sociológica desses campos. Eis alguns exemplos. Vislumbrando as relações mantidas pelos agentes sociais com um trabalho coletivamente exercido, o sociólogo pode classificar as posições assumidas por cada um deles no interior do campo em questão. Se um indivíduo está diretamente envolvido na transformação das ideias e crenças religiosas, ele é um produtor do campo religioso e encontra-se em uma posição dominante; já um outro que frequentemente se adéqua às formas de acesso e experimentação dessas ideias e crenças impostas pelos primeiros é visto como consumidor nesse mesmo campo; por sua vez quem desafia as regras vigentes na produção e no acesso a esses bens simbólicos - no caso dogmas, crenças, ritos, etc. - torna-se um concorrente do primeiro no interior desse espaço social (ver, em especial, BOURDIEU, 1998a, p. 27-78, 2007). Se Pierre Bourdieu se distancia do marxismo ao recusar a suficiência do vínculo classista para a compreensão dos agentes históricos, nem por isso ele deixa de reproduzir o modelo de conceituação da vida social centrado na categoria de trabalho que foi tão caro a Karl Marx. Ademais, essa perspectiva parece conservar certa fragrância de funcionalismo durkheiminiano (DURKHEIM, 1995). Segue-se outro caso. Examinando a linguagem com que um grupamento social concretiza a aceitação geral dessa hierarquização imposta no exercício das funções de trabalho em cada campo, Bourdieu fornecia o consensus prático que mantinha sua integração, sua coesão coletiva. Ou seja, ele desvendava aquilo que denominava como doxa que estruturava cada campo (BOURDIEU, 1998a). Por fim, nossa última demonstração: chega a ser dispensável discutir a 
centralidade do referido conceito na postura bourdieusiana de traduzir as supostas "leis" (nomos) que regem a dinâmica interna de cada campo ou "microcosmo social" em termos de monopólio, de demanda, de competição e de consumo (BOURDIEU, 1998b). Portanto, nas malhas do saber sociológico elaborado pelo autor d'O poder simbólico a ideia de trabalho é o astro solar em redor do qual orbitam as demais conceituações que viabilizam a compreensão da estruturação e dinâmica dos campos constitutivos do tecido social. O que, convenhamos, não é estranho ao que havia proposto Karl Marx quando entrelaçou os conceitos de modo de produção e formação social.

A instauração dos campos através da forma de trabalho socialmente exercida explica por que o autor insiste em considerá-los sistemas economicamente ordenados:

Os "sistemas simbólicos" distinguem-se fundamentalmente conforme sejam produzidos e, ao mesmo tempo, apropriados pelo conjunto do grupo ou, pelo menos, produzidos por um corpo de especialistas e, mais precisamente, por um campo de produção e de circulação relativamente autônomo: a história da transformação do mito em religião não se pode separar da história da constituição de um corpo de produtores especializados de discurso de ritos religiosos, quer dizer, do progresso da divisão do trabalho religioso, que é, ele próprio, uma dimensão do progresso da divisão do trabalho social [...] (BOURDIEU, 2001b, p. 12-13, grifo nosso).

Em síntese, selado pelo vigor matricial do pensamento marxista, Bourdieu fez com que os princípios de constituição de cada campo exorbitassem de um paradigma de "regras de produçãotrabalho". Isso posto, nos parece um tanto inadequada uma afirmação como esta, de que "ao introduzir a noção de trabalho religioso, porém, ele [Bourdieu] ultrapassa aqueles clássicos [Marx, Weber e Durkheim] e aporta sua maior contribuição à sociologia da religião" (TEIXEIRA, 2003, p. 181-182). Afinal, poderíamos projetar para o autor do ilustre Le sens pratique esta avaliação outrora formulada a respeito do pensamento de Karl Marx: ele 
“estende o paradigma da produção e o esquema do processo de trabalho ao real empírico e os preenche com o conteúdo desse mesmo real", sendo tal paradigma o eixo em torno do qual se articula o "trabalho das fontes, a elaboração conceitual dos dados coletados e compilados, da verificação das hipóteses, da demonstração dos teoremas e da justificação das teorias" (DOMINGUES, 2004, p. 58). Portanto, a "noção de trabalho religioso" - ou de qualquer um dos correlatos sociológicos da ideia de trabalho - adotada por Bourdieu, vista em seus alicerces, pode ser epistemologicamente subsumida no interior do pensamento de Karl Marx.

\section{A tentação: os usos medievalistas de Bourdieu}

Em nossa opinião, a grande inovação propiciada pelas obras bourdieusianas encontra-se em outro aspecto. Trata-se da forma como o sociólogo balanceou essa "macrossociologia" - esse "estruturalismo genético" (BOURDIEU, 1987) que sustenta a teoria dos campos - com contribuições particulares da "sociologia compreensiva” associada a Georg Simmel, Wilhelm Windelband, Heinrich Rickert e, especialmente, Max Weber (BOURDIEU, 1998a; COHN, 2003; FREUND, 2006; RINGER, 2004; WEBER, 2004a, 2006). Isso significa que compete a Pierre Bourdieu grande parte do mérito por ter feito com que o paradigma "trabalhoprodução" potencializasse uma maior compreensão da complexidade e das nuanças que regem as múltiplas faces da ação social. Sob esse prisma, a maior contribuição oferecida pelo autor d'O poder simbólico para a análise sociológica ou historiográfica está na abertura de novas possibilidades de exploração intelectual das inúmeras relações que regem a vida em sociedade, tanto materiais quanto simbólicas, a partir desse deslocamento e otimização de um modelo sociológico de grande fôlego teórico e versatilidade metodológica. Noutras palavras, Bourdieu magistralmente reescreveu um conhecido paradigma do saber sociológico clássico como viés de análise daqueles domínios da existência coletiva que o vocabulário filosófico do século XIX classificava como "do 
espírito" - por sua carga hegeliana -, mas que a linguagem científica do século XX - em sua forte tonalidade antropológica - habituounos a qualificar como "culturais". Desde Bourdieu é possível recorrer ao termo trabalho para referir-se aos mais diversos processos de criação envolvidos na vida social. Sua sociologia fornece-nos uma lente analítica que parece realçar, num único movimento, as relações constitutivas das facetas mais díspares e - segundo muitos autores - opostas da existência coletiva, como a elaboração de instrumentos da produção artesanal ou a criação de dogmas e rituais religiosos, ou ainda a formulação de procedimentos jurídicos ou a valorização de obras literárias. Enfim, suas ideias parecem iluminar, simultaneamente, a complexa junção de bens materiais e bens simbólicos que dá forma à constituição das sociedades (BOURDIEU, 1998b, 2002).

Dessa forma, impôs-se ao olhar sociológico o desafio de repensar a construção coletiva das razões e dos sentidos que regem a ação social - território da "sociologia compreensiva" - como componente de uma abrangente macroeconomia dos campos realçada pelo emprego sistemático e totalizador do paradigma "trabalho-produção". Bourdieu apontou um caminho viável para decifrar a articulação existente entre a racionalidade das ações/ reações individuais e as pressões gerais impostas pelos processos de distribuição das funções sociais. E o fez sem incorrer nos graves e correntes excessos de diluir, superar ou mesmo subdeterminar um desses dois conjuntos de componentes. Por isso, Bourdieu alojou no interior dos campos o babitus:

O princípio da ação não é um sujeito que se defrontaria com o mundo como se fosse um objeto numa relação de puro conhecimento, nem muito menos um "meio" capaz de exercer sobre o agente uma forma de causalidade mecânica; não se encontra na finalidade material ou simbólica da ação nem nas constrições do campo. Reside na cumplicidade entre os dois estados do social, entre a história tornada corpo e a história tornada coisa, ou melhor, entre a história objetivada nas coisas, sob a forma de estruturas e mecanismos 
(os do espaço social ou dos campos), e a história encarnada nos corpos, sob a forma de habitus [...] (BOURDIEU, 2001a, p. 183-184). ${ }^{2}$

Percebamos: o habitus está inscrito no corpo e não na consciência, afinal "o corpo está no mundo social, mas o mundo social está no corpo" (BOURDIEU, 2001a, p. 185). O habitus, portanto, deve ser encarado como sistemas duráveis de disposições práticas de ação e de percepção do (e no) mundo. Um constante e maleável processo de formação social do ser que gera valores não explicitados; princípios de ação interiorizados, mas não conscientes; modos irrefletidos de julgar, valorizar e escolher. Nos termos "pascalianos" do próprio autor, trata-se de

estruturas estruturadas predispostas a funcionarem como estruturas estruturantes, isto é, como princípio que gera e estrutura as práticas e as representações que podem ser objetivamente "regulamentadas" e "reguladas" sem que por isso sejam o produto de obediência de regras, objetivamente adaptadas a um fim, sem que se tenha necessidade da projeção consciente deste fim ou do domínio das operações para atingi-lo, mas sendo, ao mesmo tempo, coletivamente orquestradas sem serem o produto da ação organizadora de um maestro. (BOURDIEU, 1972, p. 175, tradução nossa).

Como potência criadora infraconsciente, o habitus é, portanto, uma secunda natura sustentada por um delicado e dinâmico equilíbrio entre autonomia e dependência nas relações travadas com o mundo social ("estruturante e estruturada"). Uma intricada sutura que une experiências biográficas e pertencimentos coletivos. Uma matriz inconsciente de fabricação de cálculos e projeções de condutas em meio a cenários sociais preexistentes e limitados de possibilidades comportamentais. Trata-se, em outras palavras, da "razão prática gerativa" que, maleável e duradoura, é internalizada objetivamente pelos agentes sociais e acionada por eles como parte de 
sua subjetividade de forma oblíqua, não intencional, no curso do próprio agir (BOURDIEU, 1980; 1996; 2007). Dessa forma, circunscrito na jurisdição de experiências pessoais, o habitus - fator que conduz a prática de uma modalidade social de trabalho - fornece as variáveis sociológicas capazes de flexibilizar o caráter prévio e estruturado dos campos, tornando-os espaços de um estado não permanente de relações de força:

Os campos não são estruturas fixas. São produtos da história das suas posições constitutivas e das disposições que elas privilegiam [...]. Todo campo se caracteriza por agentes dotados de um mesmo habitus. O campo estrutura o habitus e o habitus constitui o campo. O habitus é a internalização ou incorporação da estrutura social, enquanto o campo é a exteriorização ou objetivação do babitus. (THIRYCHERQUES, 2006).

Como matéria-prima de uma perspectiva analítica primordialmente relacional, o par "habitus-campo" permitiu a Bourdieu trilhar uma via media entre os principais paradigmas sociológicos do pós-guerra. Os quais estavam quase sempre dispostos nos termos dicotômicos de, por um lado, macroteorias da funcionalidade do comportamento coletivo ou, por outro, de microteorias da autonomia e centralidade do indivíduo (ALEXANDER, 1987). Dito de outra forma: o pensamento do sociólogo francês permite entrelaçar e articular o que até então era visto por muitos como grandezas antagônicas: estrutura versus fato-conjuntura, materialidade versus simbólico, objetivismo versus subjetivismo, engenharia social versus autonomia dos indivíduos.

Não demorou muito para que medievalistas brasileiros percebessem aí um valioso ás na manga para seu dilema. Filho da sociologia clássica, o pensamento bourdieusiano permitia temperar a macro-história das mentalidades por meio de flexibilizações e adaptações que não implicavam renúncias maciças àquele legado historiográfico. Se as críticas censuravam a forma como nossos "autores clássicos" engolfavam as sociedades medievais no interior de mentalidades dotadas de uma vertiginosa abrangência 
interclassista (FONTANA, 2004, p. 381-412; GINZBURG, 1987, p. 28-31), a aplicação do par campo-babitus permitia corrigir tais excessos, contemplando razões biográficas e particularidades de "microcosmos sociais", sem abrir mão do pressuposto annaliste de que a ação social se torna satisfatoriamente inteligível somente como um fenômeno coletivo e de grande amplitude societal. Se por ventura outros autores sacavam o tema da inexatidão ou mesmo de uma indiferença com que as mentalidades relacionavamse com a estratificação e dinâmica social (DOSSE, 2003, p. 247267), a teoria dos campos tornava possível conferir maior visibilidade ao peso histórico das divisões sociais sem renunciar a um postulado caro à nouvelle histoire: a existência de uma autonomia dos domínios do simbólico e do imagético. Se despontavam no horizonte recriminações de que a história das mentalidades enquadrava os processos culturais em rígidos esquemas, oscilando arbitrariamente da condição de determinados à de determinantes (CARDOSO, 1988, p. 92-114), a abordagem relacional consagrada por Bourdieu oferecia um antídoto certeiro e eficaz ao demonstrar que tal oscilação é intrínseca à vida social; e, o principal, essa demonstração não exigia que nossos medievalistas se demitissem da tarefa aclamada pelos Annales de escrever uma história proclamada como especificamente "cultural". Exemplo sintomático de toda esta argumentação é o fato de Jacques Le Goff (1999, p. 26) apresentar seu São Luis, originalmente publicado em 1996, como uma biografia norteada pelo zelo de escapar ao "falso problema da pretensa oposição entre o indivíduo e a sociedade cujo vazio foi mostrado por Pierre Bourdieu". Nossos próprios modelos historiográficos pareciam indicar a direção a ser tomada.

Em síntese: a sociologia da religião bourdieusiana acenava ao medievalista brasileiro com as chaves de ouro que lhe permitiriam desvencilhar-se dos percalços teóricos atribuídos à "história das mentalidades", sem, contudo, renunciar à poética bistoriográfica escrita pelos "pais fundadores" de seu campo de estudos (CARRARD, 1995). No pensamento de Bourdieu nossos Faustos universitários encontram a possibilidade de um pacto intelectual que impediria sua ação acadêmica criadora de esmorecer. Porém, 
tal como na obra do memorável escritor do Romantismo alemão, o pacto abrigou na própria promessa uma perigosa tentação.

O medievalista não pode negligenciar o sério e decisivo risco implícito na adoção da formidável maneira de pensar elaborada por Pierre Bourdieu. Toda a inconfundível sofisticação teórica que marca o trabalho do sociólogo não pode ofuscar a característica de que a "teoria dos campos" repousa sobre dois fundamentos teóricos moldados pela modernidade capitalista industrial. $\mathrm{O}$ primeiro deles consiste na já mencionada noção de trabalho enquanto vetor para uma dinâmica de interação social marcada por traços da economia de mercado. Será que esse léxico que distingue com tamanha clareza a "produção", a "circulação", a "concorrência" e o "consumo" de bens simbólicos pode ser indistintamente aplicado ao medievo? Nos parece no mínimo razoável indagar se essa racionalidade de um teor economicista tão singular pode ser atribuída a uma época predominantemente agrária? Por certo há muitas décadas os estudiosos destacam que o Ocidente medieval - especialmente após os séculos XII e XIII - foi o palco de avançados processos de racionalização e até mesmo de uma secularização (HASKINS, 1927; MURRAY, 1978; RADDING, 1985). Contudo, ainda assim, cabe questionar: será que a razão comportamental analisada por Bourdieu não consiste em uma variante histórica específica dos processos de racionalização? Em nossa opinião, os fortes laços epistemológicos que ligam o pensamento do sociólogo francês ao de Karl Marx é um indicador consistente que a "teoria dos campos" foi elaborada para permitir a compreensão de uma realidade histórica ocidental e que não recua para além do século XVIII. Assim, sua aplicação na escrita da história medieval imprime sobre aquele passado características extemporâneas ao mesmo, moldando-o segundo os contornos de uma realidade social posterior em um grande número de séculos.

Corroborando essa interpretação, há ainda o segundo fundamento teórico da sociologia viabilizada por Pierre Bourdieu. Trata-se de outro velho conhecido aporte dos "clássicos". Vejamos. Como concordam especialistas renomados no trabalho de nosso ilustre sociólogo, os campos resultam de processos de uma significativa diferenciação social das formas de ser e de conhecer o mundo 
(THIRY-CHERQUES, 2006; CAMIC, 1997). Sejamos mais precisos: não lidamos aqui com uma noção neutra ou genérica de "processos de diferenciação social". Muito pelo contrário, ela se refere a um processo acentuado, avançado de distinção de "microcosmos sociais". Mesmo uma leitura superficial de Bourdieu basta para constatar que, em seu pensamento, os campos não são somente recortes sociais, mas espaços socialmente delimitados por teias de valor e de sentido relativamente autônomas (conforme aparece em WEBER, 2004b). Em outras palavras, a "sociologia dos campos" segue de muito perto a conhecida característica delineada por Weber como definidora da secularização do modo vida no mundo ocidental. Ela toma como pressuposto analítico nuclear a premissa de que o conjunto social ora investigado tenha sido palco de um avançado processo de racionalização ética e de uma acentuada descentralização axiológica. Ou, visto por outro prisma, de uma dessacralização de cosmovisões tradicionais. Portanto, o sociólogo francês traz a reboque para o interior de seus estudos a conceituação notoriamente weberiana de uma sociedade povoada por fatores de desencantamento do mundo (COHN, 2003; PIERUCCI, 2005). É então que o medievalista, confrontado com a magnética obra de Bourdieu, se vê encurralado por esta indagação: é possível amparar uma investigação sobre a sociedade medieval em um cabedal conceitual ancorado no modelo de uma sociedade intensamente racionalizada e desencantada? É possível iluminar a era medieval à luz de uma teoria elaborada para o estudo da modernidade capitalista industrial?

Todas essas questões poderiam ser reformuladas como "problemas de fronteira". Pois nos parece extremamente difícil traçar uma linha demarcatória que individualize um "campo religioso" no conjunto dos domínios sociais medievais quando a vivência do sagrado era coextensiva a todo esse conjunto (SOUTHERN, 1970). Sabemos, por exemplo, que os sentidos assumidos pelas relações de poder no Ocidente medieval eram indissociáveis das experiências socialmente partilhadas acerca do "além", de "Deus", da "alma", do "pecado" ou, em termos mais gerais, de experiências hierofânicas. Assim, é uma tarefa por demais melindrosa e talvez mesmo arbitrária postular que havia, naqueles tempos, a diferenciação da matéria 
simbólica de um trabalho especificamente "político" de uma outra então transformada por um trabalho singularmente "religioso". Seria possível dizer que o "milagre" ou a "santidade", formalmente reconhecidos pela hierarquia eclesiástica, são, por princípio, construções religiosas quando os reis se faziam taumatúrgicos por séculos a fio e os regimes políticos eram instituídos por ritos e crenças nas manifestações espirituais (BLOCH, 1994)? Poderíamos dizer que se tratava de bens simbólicos cuja criação precedia a fundamentação da esfera política e que seriam, desse modo, meramente "apropriados" ou "absorvidos" como já constituídos no interior desta? Ou ainda: onde estaria a fonte de "relativa autonomia" de um desses campos em relação ao outro? Um estudioso que buscasse estabelecer limites de distinção entre o "político" e o "religioso" no interior desse passado que remonta a cerca de um milênio seria forçado a admitir tantas concessões, a reconhecer inúmeros estados de exceção nessa mesma separação, que caber-lhe-ia indagar se a irredutibilidade das leis e lógicas específicas dos tais "campos sociais" - cerne da proposição bourdieusiana - encontra-se, enfim, preservada.

Ou ainda, nos parece por demais incerta e arriscada a busca por traçar alguma fronteira que permita categorizar em separado o "econômico" e o "religioso" numa civilização em que os processos de construção da hegemonia e da dominação social criavam uma grande área de interpenetração de quadros axiológicos, tornando altamente permeáveis os valores e sentidos norteadores de diversas relações, mesmo as aparentemente mais díspares, como as lutas pela sobrevivência diária na peleja da produção agrária e as questões que envolviam os assuntos da alma na senda da eternidade (BASTOS, 2002). Em outras palavras, como insistiu há décadas Otto Brunner (1992), é necessário reconhecer que as divisões estabelecidas pela sociedade medieval entre as "regras" e os "limites" das condutas e escolhas não eram invariavelmente regidos por uma orquestração logocêntrica e funcionalista. Como essa que Bourdieu confere à prática social por meio da "sociologia dos campos".

Por certo, corremos aqui o risco de fundamentar a crítica em um certo esquematismo. Não temos dúvidas de que um modesto artigo científico, não importa qual sua extensão, não fará jus à 
complexidade e à riqueza do pensamento formulado pelo autor d'As regras da arte. Que, por sinal, é pródigo em demonstrações de como os campos não são compartimentos sociais, já que sua constituição é marcada por constantes deslocamentos axiológicos e por nebulosas zonas de contradição (BOURDIEU, 2002). Tampouco eles são isentos de permeabilidade de influências ou interligações institucionais e simbólicas. Todavia, o que realmente pretendemos colocar em debate aqui é a característica tão específica quanto basilar de que, em meio a propriedades e aspectos historicamente variáveis, os campos comportam, por pressuposto, a característica paradigmática de sempre possuírem uma lógica específica e irredutível. Em outras palavras, eles devem comportar, por princípio teórico, linhas de forças simbólicas peculiares, capazes de pesar sobre a forma como os agentes sociais se comportam, agem e operam suas escolhas. Portanto, como o sítio de um trabalho socialmente singular, um campo é sociologicamente concebido como o locus de uma singularização dos papéis sociais, como fomento de razões normativas diferenciadas no âmago das ações coletivas.

Essa argumentação pode ser contemplada através de um exemplo prático. Os aspectos "estruturados" exercidos pela teoria dos campos se fazem sentir com clareza na concepção de Bourdieu acerca da noção de "Igreja". Desdobrando como uma coerência impecável os traços conferidos à realidade teorizada do "campo religioso", nosso sociólogo define aquele conceito central para qualquer medievalista da seguinte maneira: "há igreja quando há um corpo de profissionais burocraticamente organizados, quando todas as tarefas se cumprem em uma comunidade institucionalizada" (BOURDIEU, 1998, p. 95). Logo, a Igreja consiste na forma sociológica exponencial de organização do chamado "microcosmo religioso". Cabe perguntar: onde estariam as linhas de força dessa realidade em uma civilização na qual "clérigos eruditos praticam de bom grado a magia negra, padres das zonas rurais integram costumes pagãos na liturgia, e [na qual] o quadro cristão mais ortodoxo pode prestar-se à superstição e à magia" (BOLOGNE, 1998, p. 164)? Indagações e desconfortos teóricos se multiplicam: até onde podemos levar a variante da "contraditoriedade" possível, por exemplo, ao campo religioso sem fazer com 
que ele seja estatelado por algum tipo de implosão conceitual? Sem convertê-lo em um espaço social aberto a não importa quais valores e práticas, sem que, de fato, pouco lhe reste de uma identidade ou lógica específica? O que, por conseguinte, significaria privá-lo de uma trama própria, de uma dynamis singular. Até onde ir com a medida da flexibilidade e da tensão interna de um campo sem dissolver a máxima bourdieusiana da existência de regras particulares minimamente sistematizadas e vigentes no interior desses microcosmos? Em uma palavra: quando as fontes históricas parecem desafiar a regência conceitual, qual deve possuir preferência? Os indícios do passado ou a validade do modelo teórico?

Desse modo, a adoção dessa teoria sociológica pelos medievalistas implica tantas correções, adaptações e, sobretudo, recusas que restanos questionar sobre o que paira o maior risco de uma assepsia domesticadora: o passado medieval ou a sociologia de Pierre Bourdieu.

\section{Os destinos da alma: os medievalistas e seu Mefistófeles}

À primeira vista, talvez estas páginas consistam para o leitor em uma análise do apelo realizado por muitos medievalistas brasileiros à sociologia de Pierre Bourdieu. Todavia, seu alvo foi outro. Cada uma destas páginas destinou-se a debater o imperativo institucional que leva pesquisadores a recrutar orientações teóricoconceituais que atendam antes às pressões de legitimação científica perante seus "pares". Em nossa opinião, satisfazer esse imperativo tem sido um forte estímulo para que muitos dos pesquisadores nacionais em história medieval recorram a uma aplicação descuidada - quando não automática - de matrizes teóricas forjadas para permitir a compreensão de épocas muito distantes do medievo.

Essa, sem dúvida, não é uma singularidade dos medievalistas. Nem mesmo do universo acadêmico brasileiro. Nenhum historiador está imune a pressões desse tipo. Porém, no caso da historiografia medievalista produzida em nossas universidades, elas parecem pesar de forma particularmente grave e sufocante. Nossa escrita está pautada na perspectiva de que a recente consolidação acadêmica 
do medievalismo nacional - rapidamente atingida por dilemas como o que vimos nas primeiras páginas deste artigo - e um resistente ambiente de preconceitos que teimam em estigmatizar quem se dedica a "esse passado que não é nosso", deixam vulneráveis os autores de nossa medievalística a tais pressões, constrangendoos de modos mais intensos a responder a exigências desse feitio.

Pressionado em sua legitimidade científica pela intelligentsia universitária, o estudioso brasileiro da história medieval se vê diariamente forçado a privilegiar rigorosas demandas de seus pares durante seu "fazer científico". A vencer suas contestações e cobranças. A rechaçar as investidas que ameaçam minar sua ainda limitada credibilidade científica. O apelo à "teoria bourdieusiana dos campos" é um indício dessas linhas de força institucionais que, silenciosas e avassaladoras, arrebatam o estudo do passado medieval. Capturam nossos investigadores e os compelem a metamorfosear a operação historiográfica em um jogo de espelhos dominado pelo reflexo de seus "pares". Nessa trama em que o reconhecimento corporativo - convertido no preço a ser pago pela concessão do cobiçado selo de "obra de valor" (CERTEAU, 2002, p. 72) - apodera-se do trabalho historiográfico penhorando sua cautela e rigor, a cientificidade do conhecimento histórico entrega-se a riscos tão temerários quanto aqueles que enredaram a vida de Fausto após seu nome ser estampado com sangue no perga-minho do triunfo oferecido por Mefistófeles. Porém, há outra lição, ainda mais importante, a ser tomada do personagem de Goethe: perceber que o sentido vital não reside em pactos, promessas ou triunfos, mas sim em manter-se um eterno insatisfeito que tem na incessante criação sua razão de ser e de correr riscos.

The scroll of Mephistopheles: theory, research and medievalist unfortunates in the sociological thought

Abstract: This article proposes a critical analysis, however brief, of the "social location" in which is conducted the brazilian research concerning the Medieval History. From this vast and complexto theme we highlight a specific topic: the appropriation of sociological theory formulated by Pierre Bourdieu by Brazilian medievalists in response to a major dilemma faced from the 1990s. The article is 
divided mainly into three parts: the first is to present the so-called impasse formed within the national medievalism, the second section provides a critical overview of the foundations of sociological theory of Pierre Bourdieu, and finally it follows the third part with the confrontation between the postulates guided the "sociology of the fields" and its pertinence to the study of medieval civilization. The core of this paper is to propose ideas to stimulate a most accurate debate about the intellectual reasons and the power relations that guide the exercise of the letter of medievalist in Brazil.

Keywords: Medieval History. Sociological thought. Historiography. Theory. Pierre Bourdieu.

\section{Notas}

${ }^{1}$ Tratava-se então da ressonância maior de um desconcertante sucesso que já havia tomado de assalto o meio acadêmico francês na década de 1960: "Os anos 19501960 vêem então desabrochar, em muitos países da Europa, em particular na França, um gênero novo. Editores, freqüentemente historiadores eles próprios, nos encomendam obras cuja lógica não é universitária. Ao acolher alguns de nossos projetos, esses editores se apresentam principalmente com uma força de propósitos até então desconhecida." (LE GOFF, 2005, p. 90). Ou ainda: "No curso dos anos 1960, o reaparecimento das mentalidades subverte inteiramente a historiografia francesa. Os sumários das grandes revistas, inclusive as mais conservadoras, mudam, assim como os temas de mestrado e de doutorado. [...] Essa história exorbita do pequeno círculo dos especialistas, penetra na mídia, vende-se, por vezes bem, no público mais amplo que conquistou." (LE GOFF, 1998, p. 160-161). Sobre esta temática da repercussão internacional dos nowveaux, ver ainda Hunt (1986, p. 209-224).

${ }^{2}$ Nesse ponto fica claro como Bourdieu distancia-se dos modelos epistemológicos dominantes no cenário intelectual francês nas décadas de 1950 e 1960. Ao dimensionar a racionalidade da ação individual como performática sobre o tecido social, ele se afastava do marxismo que, em sua versão althusseriana, mostrava nítida dificuldade em dimensionar o papel do indivíduo na construção do mundo social, amarrando-o a "estruturas" demasiadamente rígidas e desumanizadas, como a "ideologia". Por sua vez, inserindo o indivíduo na trama de um campo, o autor recusava ainda a implicação de um sujeito autodeterminante, imagem que então exorbitava frequentemente do existencialismo de Sartre e da fenomenologia de Husserl (PINTO, 2000). 


\section{Leandro Duarte Rust}

\section{Referências}

ALEXANDER, J. O Novo Movimento Teórico. Revista Brasileira de Ciências Sociais, v. 2 , n. 4 , p. 5-28, 1987.

BARTHES, R. Le discours de l'histoire. Information sur les Sciences Sociales, v. 6, n. 4, p. 65-75, 1967.

BASTOS, M. J. da M. Religião e hegemonia aristocrática na Península Ibérica (séculos IVVIII). Tese (Doutorado em História Social) - Faculdade de Filosofia, Letras e Ciências Humanas, Universidade de São Paulo, São Paulo, 2002.

BENOIST, J.-M. La revolution structurale. Paris: Grasset, 1975.

BLOCH, M. Os reis taumaturgos. São Paulo: Companhia das Letras, 1994.

BOLOGNE, J. C. Da chama à fogueira: magia e superstição na Idade Média. Lisboa: Dom Quixote, 1998.

BOURDIEU, P. Esquisse d'une Théorie de la Pratique. Genève: Droz, 1972.

. Le sens pratique. Paris: Les Éditions de Minuit, 1980.

. Choses dites. Paris: Les Éditions de Minuit, 1987.

- Razões práticas. Campinas: Papirus, 1996.

- A economia das trocas simbólicas. São Paulo: Perspectiva, 1998a.

- As regras da arte. São Paulo: Companhia das Letras, 1998b.

. Meditações pascalianas. Rio de Janeiro: Bertrand Brasil, 2001a.

. Opoder simbólico. Rio de Janeiro: Bertrand Brasil, 2001 b.

- A reprodução da crença. São Paulo: Zouk, 2002.

. Os usos sociais da ciência. São Paulo: Unesp, 2004.

- A distinção: a crítica social do julgamento. Porto Alegre: Zouk, 2007.

BRUNNER, O. Land and lordship: structures of governance in medieval Austria. Philadelphia: University of Pennsylvania Press, 1992.

CANTOR, N. Inventing the Middle Ages: the lives, works and ideas of the great medievalists of the twentieth century. New York: Quill, 1991.

CAMIC, C. (Ed.). Reclaiming the sociological classics: the state of the scholarship. Oxford: Blackwell, 1997.

CARDOSO, C. F. Ensaios racionalistas. Rio de Janeiro: Campus, 1988. 


\section{O pergaminho de Mefistófeles:...}

CARRARD, P. Poetics of the New History: french historical discourse from Braudel to Chartier. Baltimore: John Hopkins University Press, 1995.

CERTEAU, M. A escrita da história. Rio de Janeiro: Forense Universitária, 2002.

COHN, G. Crítica e resignação: Max Weber e a teoria social. São Paulo: Martins Fontes, 2003.

DOMINGUES, I. Epistemologia das ciências humanas. São Paulo: Loyola, 2004.

DOSSE, F. História do estruturalismo. São Paulo: Ensaio; Campinas: Edunicamp, 1994. $2 \mathrm{v}$.

. História em migalhas. Bauru: Edusc, 2003.

DURKHEIM, E. Da divisão do trabalho social. São Paulo: Martins Fontes, 1995.

FONTANA, J. A bistória dos homens. Bauru: Edusc, 2004.

FRANCO JR., H.; BASTOS, M. J. da M. L'histoire du Moyen Âge au Brésil. Bulletin du Centre d'Études Médiévales, Auxerre, n. 7, p. 125-131, 2002-2003.

FREUND, J. A sociologia de Max Weber. Rio de Janeiro: Forense Universitária, 2006.

GINZBURG, C. O queijo e os vermes. São Paulo: Companhia das Letras, 1987.

GUIMARÃES, A. P. Quatro séculos de latifúndio. São Paulo: Fulgor, 1963.

HASKINS, C. H. The Renaissance of the Twelfth Century. Cambridge: Harvard University Press, 1927.

HUNT, L. French history in the last twenty years: the rise and fall of the Annales paradigm. Journal of Contemporary History, Cambridge, v. 21, n. 2, p. 209-224, 1986.

LEFEBVRE, H. Para compreender o pensamento de Karl Marx. Lisboa: Edições 70, 1966.

LE GOFF, J. (Org.). A História Nova. São Paulo: Martins Fontes, 1998.

. São Luis: uma biografia. Rio de Janeiro: Record, 1999.

. Em busca da Idade Média. Rio de Janeiro: Civilização Brasileira, 2005.

LYOTARD, J.-F. A condição pós-moderna. Rio de Janeiro: José Olympio, 2006.

MACEDO, J. R. (Org.). Os estudos medievais no Brasil: catálogo de dissertações e teses: Filosofia, História, Letras (1990-2002). Porto Alegre: Editora da UFRGS, 2003.

MARX, K. Lineas fundamentales de la crítica de la economia politica (Grundrisse). Barcelona: Crítica, 1977. . O capital. v. 1, São Paulo: Abril Cultural, 1983. 


\section{Leandro Duarte Rust}

MEGILL, A. Coherence and incoherence in historical studies: from the Annales School to the New Cultural History. New Literary History, Baltimore, n. 35, p. $207-$ 231, 2004.

MURRAY, A. Reason and society in the Middle Ages. Oxford: Oxford University Press, 1978.

NICHOLSON, L. (Ed.). Feminism and Postmodernism. New York: Routledge, 1990.

OLIVEIRA, M. Reviravolta lingüistico-pragmática na filosofia contemporânea. São Paulo: Loyola, 2006.

PIERUCCI, A. O desencantamento do mundo: todos os passos do conceito em Max Weber. São Paulo: Editora 34, 2005.

PINTO, L. Pierre Bourdieu e a teoria do mundo social. Rio de Janeiro: FGV, 2000.

RADDING, C. A world made by men: cognition and society, 400-1200. Chapel Hill: University of North Carolina Press, 1985.

REIS, J. C. Escola dos Annales: a inovação em História. São Paulo: Paz e Terra, 2000.

RINGER, F. A metodologia de Max Weber: unificação das ciências culturais e sociais. São Paulo: Edusp, 2004.

ROBBINS, D. Sociology and philosophy in the work of Pierre Bourdieu, 19651975. Journal of Classical Sociology, London, v. 2, n. 3, p. 299-328, 2002.

RORTY, R.; GHIRALDELLI JR., P. Ensaios pragmatistas sobre subjetividade e verdade. Rio de Janeiro: DPA, 2006.

ROSDOLSKI, R. Gênese e estrutura de O Capital de Karl Marx. Rio de Janeiro: Contraponto, 2001.

RUST, L. D.; BASTOS, M. J. da M. Translatio studii: a história medieval no Brasil. Signum, São Paulo, n. 10, p. 163-188, 2008.

SILVA, A. C. L. F. da. Reflexões sobre o uso da categoria gênero nos estudos de história medieval no Brasil (1990-2003). Caderno Espaço Feminino, Uberlândia, v. 11, n. 14, p. 87-107, 2004.

SODRÉ, N. W. História da burguesia brasileira. Rio de Janeiro: Civilização Brasileira, 1976.

SOUTHERN, R. Western society and the Church in the Middle Ages. London: Penguin, 1970.

TEIXEIRA, F. (Org.). Sociologia da religião. Petrópolis: Vozes, 2003. 


\section{O pergaminho de Mefistófeles:...}

THIRY-CHERQUES, H. R. Pierre Bourdieu: a teoria na prática. Revista da Administração Pública, Rio de Janeiro, v. 40, n. 1, 2006. Disponível em http:// www.scielo.br/scielo.phpscript $=$ sci_arttext\&pid $=$ S0034761220 06000100003\&lng=en\&nrm=iso Acesso em 21 nov. 2007.

VANDENBERGHE, F. "The real is relational"; an epistemological analysis of Pierre Bourdieu's generative structuralism. Sociological Theory, v. 17, n. 1, p. 32-67, 1999.

WEBER, M. Economia e sociedade. Brasília: EdUNB; São Paulo: Imprensa Oficial, 2004a. [2 v.]

. A ética protestante e o "espirito" do capitalismo. São Paulo: Companhia das Letras, 2004b.

. A "objetividade" do conhecimento nas ciências sociais. São Paulo: Ática, 2006.

WHITE, H. Trópicos do discurso. São Paulo: Edusp, 2001.

Recebido em: 06/03/2010

Aprovado em: 05/05/2010 